\title{
PEMANFAATAN TUMBUHAN OBAT OLEH MASYARAKAT DESA GUNUNG SEMBILAN KECAMATAN SUKADANA KABUPATEN KAYONG UTARA
}

\author{
(Utilization of Medicinal Plants by the Community of Gunung Sembilan Village Sukadana \\ District North Kayong Regency)
}

\section{Muhamad Sauji, H A Oramahi, M Idham}

Fakultas Kehutanan Universitas Tanjungpura Pontianak. Jl. Daya Nasional Pontianak 78124

E-mail : muhamadsauji7@gmail.com

\begin{abstract}
Medicinal plants are one of the important components in medicine, in the form of traditional herbal concoctions and have been used since hundreds of years ago, to solve various health problems. This study aims to obtain the spesies of traditional medicinal plants used by the community in Gunung Sembilan Village in treating diseases and to know the use of medicinal plants and how to concoct medicinal raw materials. Data collection with interview and determination of responden uses a snowball sampling technique or carried out sequentially by asking for information on people who have been interviewed or contacted before the research. Observations were made, namely by walking while (without plots) making direct observations in the field together with respondents who knew about the medicinal plants. The results of interviews with the community of Gunung Sembilan Village, Sukadana District North Kayong Regency, 27 species of medicinal plants and 23 families were utilized by the community. The use of herbs is single or mixed, the most widely used are leaves (10 species or $37.04 \%)$. The most commonly used processing method is pounded (12 species or 44.44\%), and how to consume the most frequently done, which is drink (12 species or 44.44\%).
\end{abstract}

Keywords : Gunung Sembilan village community, medicinal plants.

\section{PENDAHULUAN}

Masyarakat di Kalimantan umumnya memanfaatkan berbagai jenis tumbuhan untuk pengobatan tradisional dengan mengandalkan dari habitat alaminya. Tumbuhan obat merupakan salah satu komponen penting dalam pengobatan, yang berupa ramuan jamu tradisional dan telah digunakan sejak ratusan tahun yang lalu, untuk memecahkan berbagai masalah kesehatan yang dihadapinya. Tumbuhan Hutan Berkhasiat Obat (THBO) jarang ditanam secara khusus karena masyarakat belum terbiasa dengan kegiatan budidaya. Karakter kepercayaan yang mereka yakini bahwa THBO yang dibudidayakan tidak memiliki khasiat sebaik yang diambil langsung dari alam (Noorcahyati, 2013). Hubungan antara manusia dengan lingkungan ditentukan oleh kebudayaan setempat sebagai pengetahuan yang diyakini serta menjadi sumber sistem nilai. Tumbuhan berperan sangat penting dalam kehidupan manusia, salah satunya yaitu sebagai bahan untuk pengobatan, dan tumbuhan obat ini tidak juga hanya untuk 
kepentingan ekonomi masyarakat lokal tetapi juga untuk kepentingan budaya pada suatu kelompok masyarakat. Setiap masyarakat lokal memiliki pengetahuan yang berbeda-beda dalam pengolahan sumber daya alam sesuai dengan adat dan budaya setempat berdasarkan pengetahuan yang berakar pada tradisi tertentu. Sistem pengetahuan yang dimiliki oleh masyarakat secara tradisi ini merupakan salah satu bagian dari suku bangsa asli dan petani pedesaan (Rahayu, 2006)

Kalimantan barat dengan hutan tropika basahnya yang menyimpan berbagai jenis spesies tumbuhantumbuhan yang sering digunakan masyarakat secara tradisional. Jenis-jenis tumbuhan obat mencakup tanaman lapisan terbawah, liana, terna, perdu dan berbagai jenis pohon, dengan bagian tumbuhan yang digunakan berupa akar, kulit batang, kayu, daun, bunga maupun biji (Yusro, 2010). Peranan pengobatan tradisional terhadap kesehatan masyarakat cukup berarti dan tidak boleh di abaikan eksistensinya. Beberapa hasil penelitian yang terdahulu ternyata di masing-masing daerah yang ada di Kalimantan Barat ini banyak ditemukan jenis-jenis tumbuhan obat seperti di Desa Sejahtera Kecamatan Sukadana Kabupaten Kayong Utara pemanfaatan tumbuhan obat oleh battra diperoleh 78 spesies (Aminah S. 2016). Penelitian yang dilakukan (Liyanti, 2015) di Desa Pesaguan Kanan Kecamatan Matan Hilir Selatan Kabupaten Ketapang terdapat 73 jenis.

Masyarakat Desa Gunung Sembilan Kecamatan Sukadana Kabupaten Kayong Utara secara turun temurun dari generasi ke generasi yang diwariskan untuk mengobati berbagai macam jenis penyakit dengan menggunakan obat tradisonal yaitu dari tumbuhan yang ada di sekitar lingkungan tempat tinggal mereka. Masalahnya belum ada data tentang jenis tumbuhan obat yang dimanfaatkan di Desa Gunung Sembilan. Penelitian ini bertujuan untuk mendapatkan jenis tumbuhan obat tradisional serta mengetahui cara pemanfaatan tumbuhan obat antara lain cara meramu bahan baku obat, cara pengobatan dan khasiatnya oleh masyarakat Desa Gunung Sembilan Kecamatan Sukadana Kabupaten Kayong Utara.

\section{METODE PENELITIAN}

Penelitian ini dilakukan di Desa Gunung Sembilan Kecamatan Sukadana Kabupatan Kayong Utara. Alat dan bahan yang digunakan yaitu peta kawasan, buku ragam tumbuhan berkhasiat obat jilid I dan II , kamera digital, dan quisioner/daftar pertanyaan untuk responden terpilih. Penelitian ini menggunakan metode survei, pengumpulan data menggunakan teknik wawancara, penentuan responden dengan snowball sampling atau dilakukan secara berantai dengan meminta informasi pada orang yang telah di wawancarai atau dihubungi sebelumnya demikian seterusnya (Nurhaida, 2015). Berdasarkan teknik tersebut, sampel dipilih berdasarkan rekomendasi dari orang yang satu ke orang lain yang sesuai dengan penelitian untuk di wawancarai. Peneliti meminta rekomendasi dari kepala desa tentang calon responden dan rekomendasi lain yang sesuai dengan penelitian yang mengetahui tentang tanaman obat. Analisis 
data hasil wawancara langsung tentang pemanfaatan tumbuhan obat yang meliputi jenis tumbuhan, famili, bagian yang digunakan, cara pengolahan, cara penggunaan, manfaatnya, data pengembangan atau budidaya dan keberadaan tumbuhan obat, data tersebut dianalisis secara deskriptif sehingga diperoleh gambaran data tersebut secara sistematis dan akurat.
Spesies Tumbuhan Obat yang Dimanfaatkan Masyarakat Desa Gunung Sembilan Kecamatan Sukadana Kabupaten Kayong

Masyarakat Desa Gunung Sembilan Kecamatan Sukadana Kabupaten Kayong Utara yang memanfaatkan tumbuhan obat sebanyak 27 spesies dan 23 famili. Tumbuhan obat yang dimanfaatkan disajikan pada tabel 1 .

\section{HASIL DAN PEMBAHASAN}

Tabel 1. Daftar Spesies dan Famili Tumbuhan Obat yang Dimanfaatkan Masyarakat Desa Gunung Sembilan Kecamatan Sukadana Kabupaten Kayong Utara (List of Species and Famili of Medicinal Plants Utilizid by the Village Community of Gunung Sembilan Sukadana Kayong Utara District)

\begin{tabular}{lllll}
\hline No & Nama Lokal & Nama Latin & Famili & Habitus \\
\hline $\mathbf{1}$ & \multicolumn{1}{c}{$\mathbf{2}$} & $\mathbf{3}$ & $\mathbf{4}$ & $\mathbf{5}$ \\
\hline 1 & Asam Kandis & Mangifera pajang & Anacardiaceae & Pohon \\
2 & Bawang merah & Allium cepa L & Liliaceae & Herba \\
3 & Belimbing & Averrhoa carambola & Oxalidaceae & Pohon \\
4 & Cengkodok & Melastoma malabathricum & Malastomaceae & Perdu \\
5 & Cekur & Kaemferia galanga & Zingiberaceae & Herba \\
6 & Jambu Batu & Psidium guajava L & Myrtaceae & Pohon \\
7 & Jereng & Pithecollobium jiringa & Leguminaceae & Pohon \\
8 & Keladi & Colocasia sp & Araceae & Herba \\
9 & Kelapa & Cocos nucifera & Arecaceae & Pohon \\
10 & Ketepeng & Cassia alata & Leguminosae & Perdu \\
11 & Kumis kucing & Orthosiphon aristatus & Lamiaceae & Perdu \\
12 & Kunyit & Curcuma domiestica & Zingiberaceae & Perdu \\
13 & Limau nipis & Citrus aurantifolia & Rutaceae & Pohon \\
14 & Lengkuas & Languas galanga L. Wild & Zingiberaceae & Herba \\
15 & Lalang & Imperata cylindrica L & Cyperaceae & Herba \\
16 & Lidah Buaya & Aloe vera & Aspholdelaceae & Herba \\
17 & Liak & Zingiber officinale & Zingiberaceae & Herba \\
18 & Mengkudu & Morinda citrifolia L & Rubiaceae & Pohon \\
19 & Nangkak belanda & Anonam muricata L & Anonaceae & Pohon \\
20 & Pepaya & Carica papaya & Caricaceae & Pohon \\
21 & Putri Malu & Mimosa pudica & Mimosaceae & Herba \\
22 & Pugaga & Cantella asiatica & Apiaceae & Herba \\
23 & Pinang & Areca cathecu L & Arecaceae & Pohon \\
24 & Serai & Cymbopogun nardus L & Poaceae & Herba \\
25 & Sungkai & Peronema canescane & Verbenaceae & Pohon \\
26 & Sirih & Piper batle & Piperaceae & Liana \\
27 & Simpur & Dillenia excelsa & Dilleniaceae & Pohon \\
\hline & & & &
\end{tabular}


Masyarakat Desa Gunung Sembilan memanfaatkan tumbuhan obat berdasarkan pengetahuan yang diwariskan orang tuanya secara turuntemurun, sehingga dalam hasil wawancara didapatkan 27 jenis

Tabel 2. Daftar Tumbuhan Obat yang Dimanfaatkan Masyarakat desa Gunung Sembilan Berdasarkan Bagian yang Digunakan, Cara Pengolahan, Cara Penggunaan dan Manfaatnya (List of Medicinal Plants Used by the Community of Gunung Sembilan Village Based on the Section Used, Dosage, How to Process, How to Use and Its Benefits)

\begin{tabular}{|c|c|c|c|c|c|}
\hline No & Nama Lokal & $\begin{array}{l}\text { Bagian yang } \\
\text { di gunakan }\end{array}$ & $\begin{array}{l}\text { Cara } \\
\text { pengolahan }\end{array}$ & $\begin{array}{l}\text { Cara } \\
\text { penggunaan }\end{array}$ & Manfaatnya \\
\hline 1 & 2 & 3 & 4 & 5 & 6 \\
\hline 1 & Asam kandis & Getah & Langsung & Dioles & Bisul, luka dan sariawan \\
\hline 2 & Bawang merah & Rimpang & Ditumbuk & Ditempel & Luka, dan mengatasi pendarahan \\
\hline 3 & Belimbing & Daun & Direbus & Diminum & Menurunkan tekanan Darah tinggi \\
\hline 4 & Cengkodok & Daun & Ditumbuk & Ditempel & Untuk mengobati Luka \\
\hline 5 & Cekur & Rimpang & Ditumbuk & Ditempel & Bengkak, mengobati masuk angin \\
\hline 6 & Jambu batu & Daun & Direbus & Diminum & Diare, dan sakit perut \\
\hline 7 & Jering & Buah & Direbus & Diminum & Kejengkolan \\
\hline 8 & Keladi & Getah & Langsung & Dioles & Untuk mengobati luka baru \\
\hline 9 & Kelapa & Buah & Langsung & Diminum & Untuk mengobati kerumut \\
\hline 10 & Ketepeng & Daun & Ditumbuk & Dioleskan & Penyakit kulit \\
\hline 11 & Kumis kucing & Daun & Direbus & Diminum & Pelancar kencing dan sakit pinggang \\
\hline 12 & Kunyit & Rimpang & Ditumbuk & Dioles & Untuk habis bersalin \\
\hline 13 & Limau nipis & Buah & Langsung & Diminum & Untuk mengobati batuk \\
\hline 14 & Lengkuas & Rimpang & Ditumbuk & Dioles & Untuk mengobati nyeri otot \\
\hline 15 & Lalang & Akar & Direbus & Diminum & Panas dalam, dan air kencing kuning \\
\hline 16 & Lidah buaya & Lendir & Langsung & Dioles & Menghitamkan rambut \\
\hline 17 & Liak & Rimpang & Ditumbuk & Diminum & Menghangatkan tubuh \\
\hline 18 & Mengkudu & Buah & Diparut & Diminum & Untuk mengobati diabetes \\
\hline 19 & Nangkak belanda & Daun & Direbus & Diminum & Darah tinggi \\
\hline 20 & Pepaya & Daun & Direbus & Dimakan & Malaria dan menjaga stamina \\
\hline 21 & Putri malu & Seluruh & Direbus & Diminum & Berak darah dan sakit pinggang \\
\hline 22 & Pugaga & Seluruh & Direbus & Diminum & Panas tinggi dan bisul \\
\hline 23 & Pinang & Buah & Ditumbuk & Dioles & Sariawan dan sakit kepala \\
\hline 24 & Serai & Batang & Ditumbuk & Ditempel & Patah/keseleo \\
\hline 25 & Sungkai & Daun & Ditumbuk & Dioles & Panu/gatal-gatal \\
\hline 26 & Sireh & Daun & Ditumbuk & Ditempel & Mimisan, sakit mata, batuk keputih \\
\hline 27 & Simpur & Daun & Ditumbuk & Dioles & Hal magic \\
\hline
\end{tabular}

\section{Spesies Tumbuhan Obat Berdasarkan} Habitus

Sedangkan tingkat habitusnya paling banyak digunakan yaitu mulai dari herba, tumbuhan obat yang sering digunakan masyarakat untuk mengobati penyakit. Seperti bagian yang digunakan, cara pengolahan, cara penggunaan dan manfaatnya dapat dilihat pada Tabel 2 . 


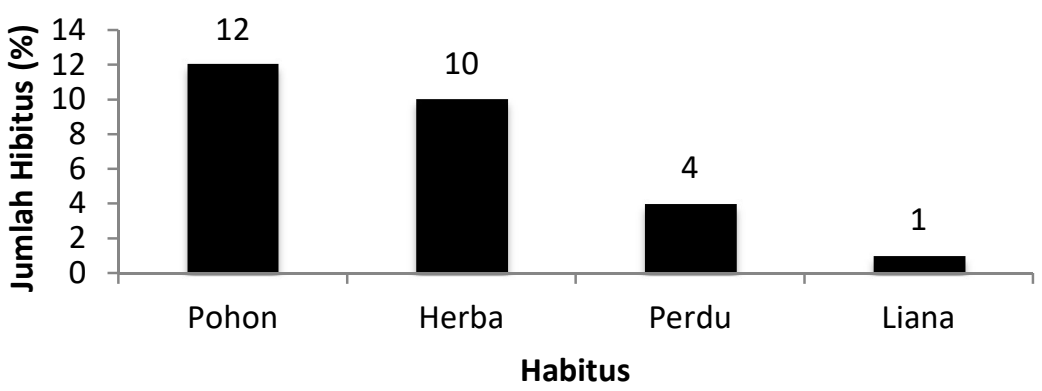

Gambar 1. Persentase Pemanfaatan Tumbuhan Obat Berdasarkan Habitus (The Percentage of Medicinal Plants Utilization Based on Habitus)

\section{Spesies Tumbuhan Obat}

Berdasarkan Bagian yang Digunakan

Bagian yang digunakan masyarakat untuk obat berupa akar, buah, batang, daun, getah, lendir, rimpang dan seluruh bagian. Bagian tumbuhan yang paling banyak digunakan adalah bagian daun yaitu 10 spesies. Selengkapnya dapat dilihat gambar 2 .

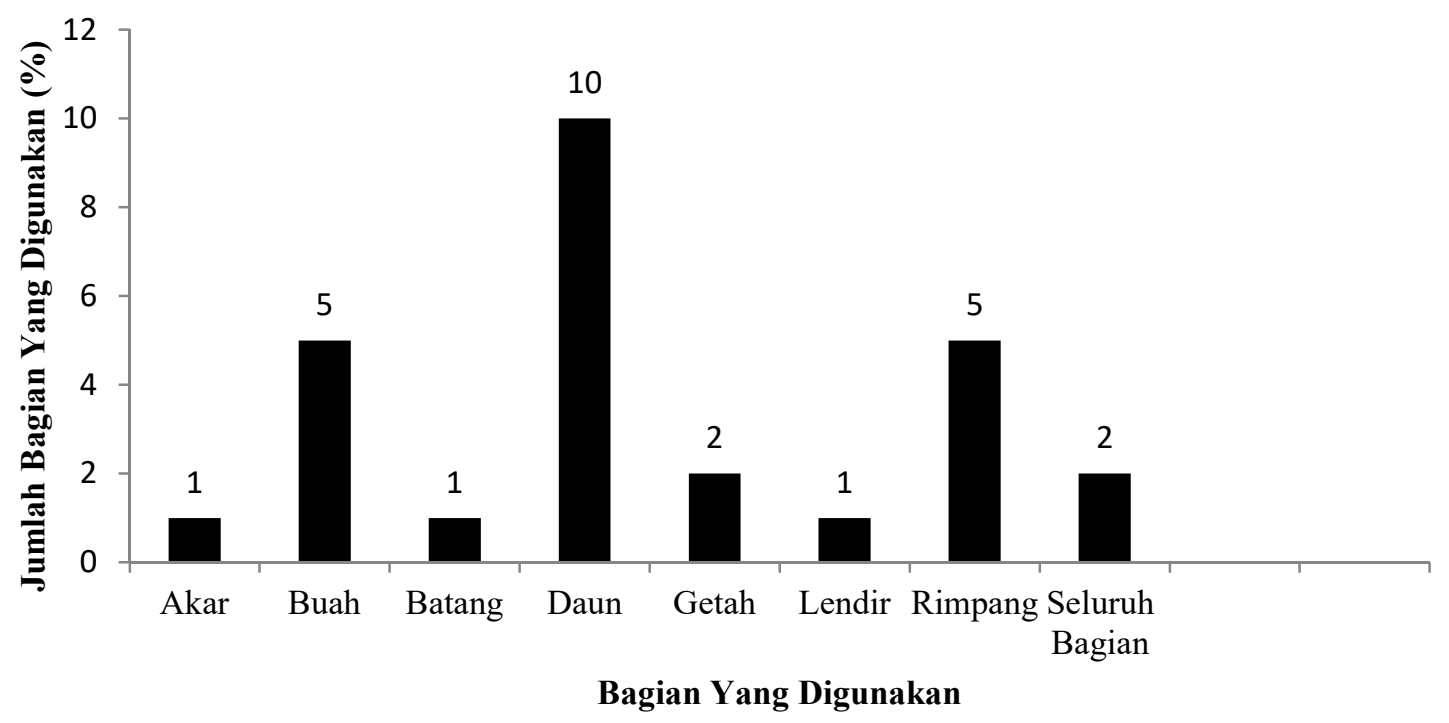

Gambar 2. Persentase Pemanfaatan Tumbuhan Obat Berdasarkan Bagian yang Digunakan (The Percentage of Medicinal Plants Utilization Based on the Part Used).

Spesies Tumbuhan Obat

\section{Berdasarkan Cara Pengolahan}

Cara pengolahan ada 4 yaitu direbus, ditumbuk, diparut dan langsung dimakan tanpa diolah. Keempat cara tersebut ternyata pengolahan dengan cara ditumbuk paling banyak digunakan yaitu sebanyak 12 spesies. Jumlah spesies berdasarkan cara pengolahan selengkapnya dapat dilihat pada gambar 3. 


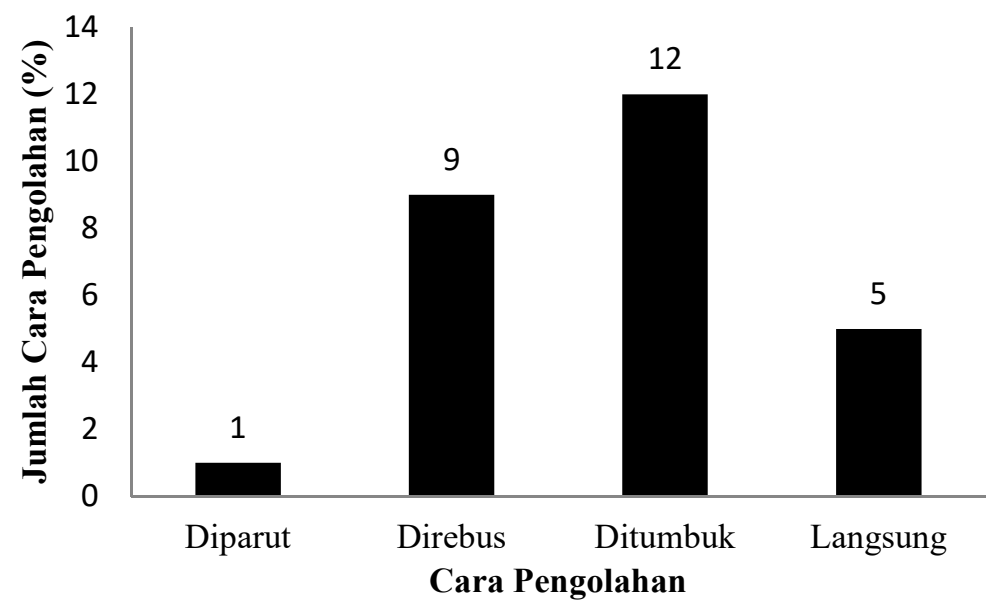

Gambar 3. Persentase Pemanfaatan Tumbuhan Obat Berdasarkan Cara Pengolahan (The Percentage of Medicinal Plants Utilization Based on Processing Methods)

Spesies Tumbuhan Obat Berasarkan

\section{Cara Penggunaan}

Berdasarkan cara penggunaannya ada 4 yaitu dimakan, diminum, dioles, ditempel. Cara penggunaan paling banyak yaitu dengan cara diminum sebanyak 12 spesies, selengkapnya dapat di lihat pada gambar 4.

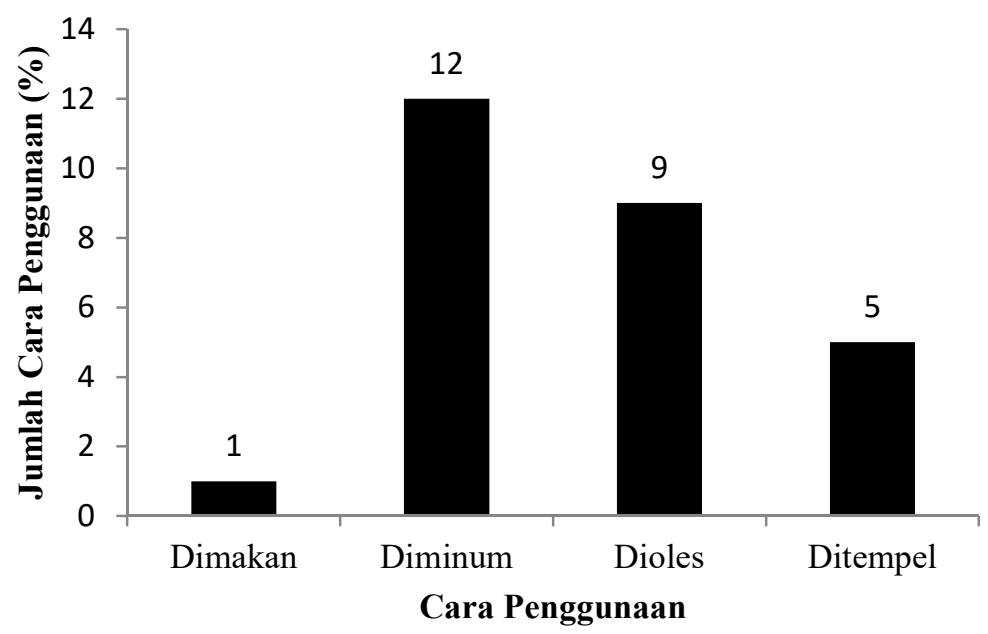

Gambar 4. Persentase Tumbuhan Obat Berdasarkan Cara Penggunaannya (The Percentage of Medicinal Plants Utilization Based on How They Are Use)

Spesies Tumbuhan Obat

\section{Berdasarkan Bentuk Ramuan}

Berdasarkan bentuk ramuan yaitu ramuan tunggal yang banyak digunakan yaitu 26 spesies dan campuran 1 spesies. Selengkapnya dapat di lihat pada gambar 5. 


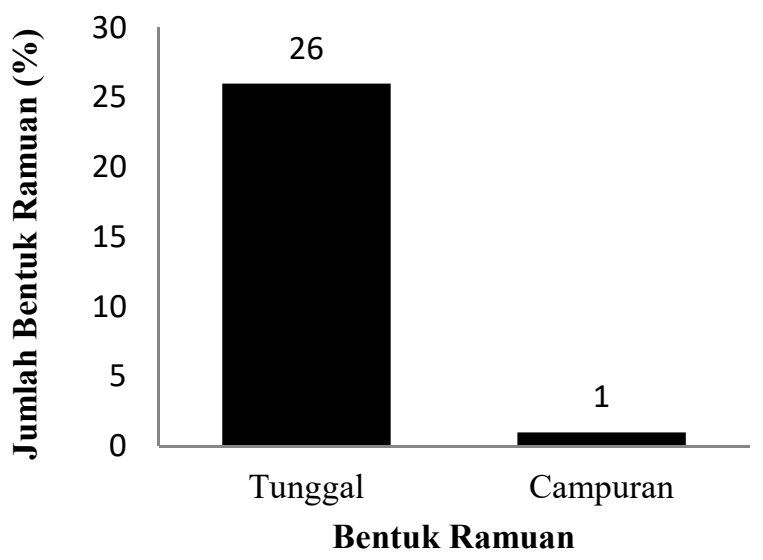

Gambar 5. Persentase Pemanfaatan Tumbuhan Obat Berdasarkan Bentuk Ramuan (The Percentage of Medicinal Plants Utilization Based on a Potion Form)

\section{Spesies Tumbuhan Obat Berdasarkan} Kegunaan

Berdasarkan kegunaannya untuk mengobati penyakit dalam ada 13 spesies

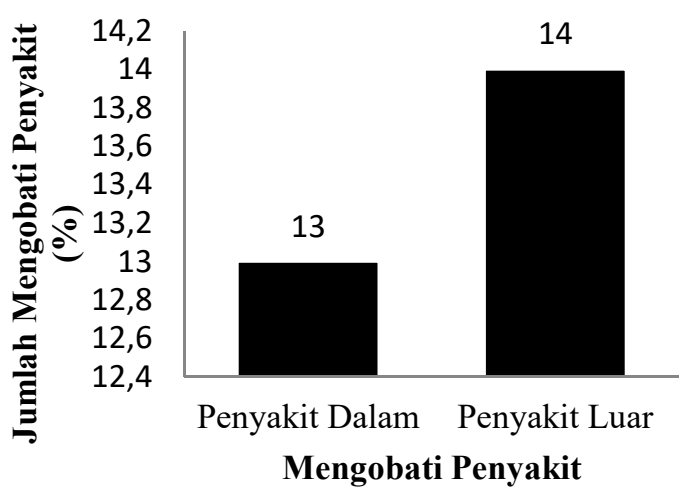

Gambar 6. Persentase Pemanfaatan Tumbuhan Obat Berdasarkan Cara Kegunaan Untuk Mengobati Penyakit (The Percentage of Medicinal Plants Utilization Based on Treat Diseases)

Seiring berjalannya waktu penggunaan tumbuhan obat secara tradisional dipengaruhi oleh budaya setempat yang berlaku secara turun temurun. Tumbuhan obat yang akan dimanfaatkan masyarakat sebagai obat bisa didapatkan di lingkungan sekitar tempat tinggal mereka seperti di lereng gunung, di pinggir jalan, di ladang maupun yang sudah dibudidayakan. Sebenarnya tumbuhan yang ada di sekitar Desa dan penyakit luar ada 14 spesies. Selengkapnya dapat dilihat gambar 6 . 
masyarakat karena mudah didapat. Masyarakat juga tidak perlu mengeluarkan biaya yang besar bila dibandingkan dengan obat-obatan modern. Masyarakat yang bertempat tinggal di sekitar lokasi penelitian ini sebagian tergolong masyarakat yang kurang mampu, karna biaya untuk berobat ke rumah sakit itu mahal dan perjalanan untuk menuju ke rumah sakit sangat jauh, oleh karna itu sebagian masyarakat memilih alternatif pertama yaitu pengobatan secara tradisional, bila tidak ada perubahan dengan pengobatan secara tradisional tersebut maka segera dibawa kerumah sakit. Masyarakat di Desa Gunung Sembilan tersebut tidak khawatir dengan penggunaan obat tradisional ini, karena tidak memiliki efek samping bila dibandingkan dengan obat-obatan modern.

\section{Kesimpulan}

Hasil penelitian terhadap jenis tumbuhan dan pemanfaatannya oleh masyarakat Desa Gunung Sembilan Kecamatan Sukadana Kabupaten Kayong Utara, tumbuhan obat yang dimanfaatkan masyarakat secara turun temurun sebanyak 27 spesies dan 23 famili. Ramuan yang digunakan $99 \%$ tunggal dan $1 \%$ campuran, pengolahan yang paling banyak dilakukan yaitu dengan cara ditumbuk $12 \%$ dan direbus $9 \%$. Pengobatan yang sering digunakan yaitu dengan cara diminum $12 \%$ dan dioles $9 \%$.

\section{Saran}

Guna tetap terpelihara pengetahuan tentang jenis-jenis tumbuhan obat serta pemanfaatannya, Sebaiknya masyarakat Desa Gunung Sembilan perlu membudidayakan tumbuhan obat diperkarangan rumah, agar kesinambungan bahan obat tetap terjaga dan mudah diperoleh. Perlu penyuluhan dan dibuat percontohan tanaman pekarangan di halaman kantor Desa Gunung Sembilan, agar masyarakat termotivasi untuk memanfaatkan perkarangannya dengan tanaman obat agar lebih berkembang.

\section{DAFTAR PUSTAKA}

Aminah S, Wardenar E, Muflihati. 2016. Tumbuhan Obat Yang Dimanfaatkan Oleh Battra Di Desa Sejahtera Kecamatan Sukadana Kabupaten Kayong Utara. Jurnal Hutan Lestari . Vol.4 (3) : 299-305.

Liyanti, Budi S, Yusro F. 2015. Studi Etnobotani Tumbuhan Yang Dimanfaatkan Di Desa Pesaguan Kanan Kecamatan Matan Hilir Selatan Kabupaten Ketapang. Jurnal Hutan Lestari, 3 (3) :421-433.

Noorcahyati. 2013. Tumbuhan Berkhasiat Obat Etnis Kalimantan Barat.Balai Penelitian Teknologi Konsevasi SDA Badan Penelitian dan Pengembangan Kehutanan.

Nurhaida, Usman FH, Tavita GE. 2015. Studi Etnobotani Tumbuhan Obat di Dusun Kelampuk Kacamatan Tanah Pinoh Barat Kabupaten Melawi. Jurnal Hutan Lestari. Vol 3 (4) :526537.

Rahayu M. 2006. Pemanfaatan Tumbuhan Obat Secara Tradisional Oleh Masyarakat Lokal Di Pulau Wawonii, Sulawesi Tenggara. Jurusan Biologi FMIPA UNS Surakarta. BIODIVERSITASVolume 7, Nomor 3 Halaman: 245-250. 